\title{
Mecanismos de Reacções nas Águas Naturais
}

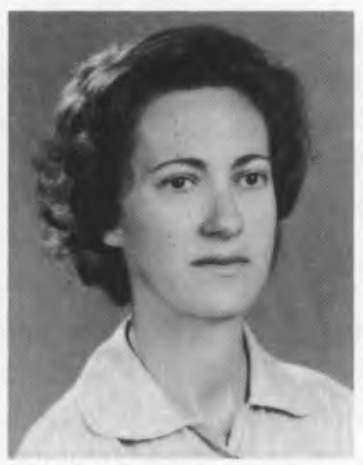

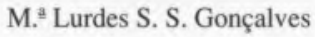

Professora Associada do Instituto Superior Técnico.

Licenciatura em Ciências Físico-Químicas - Faculdade de Ciências da Universidade de Lisboa (1963).

Doutoramento - Instituto Superior Técnico 1973.

Agregação - Instituto Superior Técnico 1984.

É professora responsável pela cadeira de Métodos Instrumentais de Análise e co-responsável pela cadeira de Controlo de Poluição da Secção de Química Analítica do curso de Engenharia Química. Colaborou em cursos do Fundo Social Europeu e de Mestrado.

Foi vários anos Coordenadora da Seç̧âo de Química Analítica e um ano representante ao Conselho Científico.

Foi responsável pelo Simpósio de Química Analítica e Ambiente, Encontro de Química, Dezembro 1988, pertenceu a várias comissões científicas de conferências nacionais sobre o ambiente e foi várias vezes "chairman" de reuniōes internacionais sobre águas naturais.

É desde 1979-1980 responsável pelo projecto de investigação do Centro de Química Estrutural do INIC (Complexo I) sobre "Especiação em Águas Naturais».

Dentro deste âmbito foi orientadora ou co-orientadora de três doutoramentos, tendo-se formado um núcleo de investigação cujo objectivo global é a interpretação dos problemas do ambiente, baseada no conhecimento dos processos químicos fundamentais. É responsável por um projecto da JNICT sobre Equilíbrio, Cinética e Adsorção nas Águas Naturais, por um outro do PEDIP sobre Interaç̧ões de iões metálicos com partículas biogénicas e inorgânicas nas águas naturais e foi responsável por um projecto NATO sobre "Development of rapid flow-injection titration for the analysis of natural waters".
Realizou vários estágios sobre temas relacionados como ambiente. Em termos internacionais mantém projectos de investigação em colaboração com a Universidade Técnica de Zurique e a Universidade de Geneve da Suíça bem como como o Plymouth Marine Laboratory (Inglaterra).

A nível nacional tem colaboração com o Instituto Nacional de Investigação das Pescas (INIP), o Instituto Hidrográfico (IH), o Laboratório Nacional de Engenharia e Tecnologia Industrial (LNETI), o Serviço Nacional de Parques, Universidade Nova de Lisboa, Faculdade de Engenharia do Porto, Universidade do Algarve, Universidade do Minho e Faculdade de Ciências de Lisboa, além da existente com outros grupos do Centro de Química Estrutural e do Instituto Superior Técnico.

Dentro deste âmbito é co-orientadora de várias teses de doutoramento sobre temas ligados ao ambiente.

Publicou mais de 50 artigos em revistas nacionais e internacionais e 2 livros didácticos.

As águas naturais são meios complexos onde existem vários catiões e ligandos inorgânicos e orgânicos em solução que podem interactuar entre si, devendo também considerar-se as interfaces água/ar e água/sedimentos ou partículas em suspensão, bem como as interacções com os organismos vivos que afectam e são afectados pela química do ambiente. A composição dos ecossistemas naturais pode ser muito variável, desde as águas doces pouco salinas (rios, lagos, etc.), até à água do mar com força iónica de $0.7 \mathrm{M}$, passando pelas águas dos estuários em que há uma variação muito brusca da salinidade. Esta variação provoca aglomeração das partículas coloidais, devido à neutralização das cargas superficiais, que vão sedimentando e em grande parte não passam para o oceano. Com uma grande percentagem dos iões metálicos e dos compostos orgânicos provenientes dos organismos vivos, ou devido à poluição, estão adsorvidos nas partículas em suspensão, ficam retidos nos estuários e não passam para o mar, devendo-nos lembrar contudo que podem voltar para a solução se as características desta variarem, por exemplo devido a uma chuva ácida, ou a alterações das suas propriedades complexantes provocadas por um esgoto urbano ou doméstico.

${ }^{a}$ Centro de Química Estrutural - Complexo I, Instituto Superior Técnico, Av. Rovisco Pais, 1096 Liboa Codex. 
Como as partículas em suspensão controlam grande parte dos mecanismos nas águas naturais é importante estudar, em qualquer projecto de investigação deste tipo, as interacções possíveis entre as espécies em solução e a fase sólida dispersa.

Neste contexto são importantes os organismos vivos que libertam compostos orgânicos que podem aumentar a solubilidade dos metais (ex: sideróforos em geral com grupos hidroxamato com grande afinidade para o $\mathrm{Fe}(\mathrm{III})$ ), mas que podem também ficar adsorvidos nas partículas inorgânicas em suspensão, controlando a sedimentação dos metais adsorvidos. Este papel interfacial dos compostos orgânicos pode ser mais importante do que a simples complexação em solução, actuando como intermediários nas interacções metal/ organismo e no controlo dos ciclos geoquímicos dos metais nos sistemas aquáticos.

A formação de complexos de superfície é em geral mais importante que em solução, a não ser possivelmente nas águas intersticiais dos sedimentos, em águas costeiras com grande produtividade, ou em águas poluídas, pois que os teores de compostos orgânicos e metais pesados são em geral baixos e os compostos orgânicos libertados pelos seres vivos são normalmente complexantes fracos, além de haver a competição dos alcalino-terrosos. É no entanto de salientar que estes têm maior afinidade para os ligandos oxigenados, ao contrário dos metais pesados, que se ligam preferencialmente aos ligandos azotados e sulfurados. A competição depende do produto $\beta[\mathrm{L}]$ em que $\beta$ é a constante de estabilidade e [L] a concentração de ligando livre. Actualmente sabe-se, por exemplo, que o cobre(II) pode estar largamente presente na forma de complexos orgânicos solúveis e que uma fracção de ferro pode estar ligada a sideróferos, compostos orgânicos produzidos pelo plancton para captar este elemento esssencial, que se encontra em grande parte precipitado, na forma de hidróxido de ferro(III), nas águas superficiais.

Um outro papel importante dos metabolitos extracelulares é o de poderem servir de doadores electrónicos entrando em reacção redox e provocando a redução de alguns iões metálicos. Assim, por exemplo, tem-se detectado Fe(II) nalgumas culturas de laboratório em presença de oxigénio, o que aumenta a disponibilidade do ferro para o fitoplancton, tendo-se verificado que esta reacção é acelerada pela luz solar.

Sabe-se também que os compostos húmicos e fúlvicos provenientes da degradação das plantas, e que representam uma fracção apreciável da matéria orgânica na águas naturais não poluídas, exercem o mesmo efeito redutor no ferro(III), devendo o processo ser particularmente intenso na águas superficiais devido à presença de luz solar e próximo das camadas anóxicas (teor mínimo de oxigénio dissolvido), onde a tendência redutora deve ser máxima.

É também importante saber em que condições certos iões podem actuar como catalisadores para a oxidação de certos compostos no meio ambiente, como é o caso do cobre(II) que em certas condições se pode reduzir a cobre(I) provocando por exemplo a oxidação do sulfito a sulfato no meio ambiente.

Por outro lado, tem-se verificado que a disponibilidade de certos metais vestigiários como microconstituintes essenciais, ou como elementos tóxicos para os organismos planctónicos, é dependente das espécies químicas em solução. Tem-se notado por exemplo que, exceptuando o caso de complexos lipossolúveis como os compostos metilados ou etilados, a captação de muitos iões metálicos por determinados seres vivos depende da concentração, ou actividade do ião livre em solução. Deste modo os efeitos dos metais nos organismos são provavelmente controlados por uma reacção entre o ião metálico e um determinado grupo celular.

$$
\mathrm{M}+\mathrm{X} \rightleftarrows \mathrm{MX}\left(\mathrm{K}_{\mathrm{x}}\right)
$$

que pode estar no interior da célula, ou à sua superfície, sendo o estado de equilíbrio, ou pseudo-equilíbrio, controlado pela actividade do ião metálico livre.

É importante salientar que isto não implica que o ião livre seja a espécie que atravessa a membrana biológica como tem sido por vezes referido. No entanto como são as actividades dos iões livres que controlam as interacções com os organismos vivos, tem interesse conhecer estes valores, embora sejam difíceis de determinar experimentalmente. Com efeito poderiam ser determinados usando as técnicas potenciométricas com eléctrodos específicos, que no entanto estão limitadas em termos de sensibilidade e interferentes, podendo ser substituídas pelas técnicas voltamétricas, muito embora estas não determinem directamente o ião livre, mas simplesmente os complexos lábeis durante a escala tempo do método e eventualmente complexos não lábeis redutíveis a potenciais mais negativos.

A actividade dum ião livre em solução pode também ser determinada por cálculos computacionais, considerando que se está numa situação de equilíbrio, muito embora se saiba estarem as águas naturais desviadas desta situação, em especial devido aos organismos vivos, à fotossíntese e a reacções de precipitação, redox ou a mecanismos de mistura muitas vezes lentos. No entanto, como os sistemas ecológicos tendem para uma situação de equilíbrio esta aproximação tem interesse, desde que se considerem os valores das contantes de estabilidade determinadas para o meio em questão, visto que os cálculos são muito dependentes destes parâmetros termodinâmicos.

$\mathrm{O}$ aspecto cinético tem também que ser considerado, visto que se as reacções químicas forem rápidas comparadas com o tempo de residência ou permanência dos elementos, podese considerar que se está numa situação de equilíbrio, se forem muito lentas pode-se ainda admitir uma situação de pseudo-equilíbrio, mas numa situação intermediária tem que se atender à velocidade das reacções quando da interpretação dos mecanismos presentes.

Em última análise, quando se pretendem fazer estudos de mecanismos nas águas naturais, deve-se tentar compreender de que modo o meio ambiente responde a uma perturbação que lhe é imposta do exterior e em que medida os mecanismos reguladores podem controlar de novo o processo.

Trata-se dum estudo bastante complexo, em que é necessário compreender não só os mecanismos em solução, mas também os processos de interface, incluindo as interacções com organismos vivos. Deste modo, devem fazer-se estudos com modelos laboratoriais em que as várias variáveis estejam controladas, determinando constantes de equilíbrio, constantes de velocidade e constantes de adsorção nas interfaces, que 
permitam fazer cálculos simulando o que se passa no meio ambiente. Em paralelo deverão ser feitos estudos directamente no meio ambiente, ou em modelos cada vez mais perto da realidade, que deverão ser comparados com os resultados obtidos nas simulações computacionais obtidas com os parâmetros determinados. Deverá, no entanto atender-se a que o método analítico interactua sempre, em maior ou menor grau, com as reacções do meio natural e que se deverá ter todo o cuidado com problemas de contaminação ou adsorção nas paredes dos recipientes, em especial quando se determinam teores muito baixos, devendo também fazer-se as análises o mais rapidamente possível após a amostragem, que deverá ser significativa da amostra real.

É dentro desta perspectiva que o nosso projecto de investigação tem vindo a ser realizado, embora se divida em vários temas por uma questão de simplicidade:

\section{a) Estudos de mecanismos em soluçâo nas águas naturais}

Dentro deste tema determinámos por métodos electroquímicos constantes de estabilidade e constantes de velocidade de sistemas químicos com importância nas águas naturais, como os clorocomplexos de cobre(II), cobre(I) e cádmio e os complexos de cádmio, cobre, chumbo e zinco com aminoácidos nas condições da água do mar, dos complexos de uranilo e vanadilo com grupos quelantes da matéria húmica e dos complexos de ferro com ácidos hidroxâmicos substituídos.

Também se determinaram as constantes de estabilidade macroscópicas e microscópicas de cobre(II), zindo(II) e chumbo(II) com uma proteína - o citocroma C - para se tentar compreender quais os tipos de grupos envolvidos na complexação e o teor em que eles existem à superfície da proteína.

Fizeram-se também estudos de redução do cobre(II) pelo ião sulfito e analisou-se a influência do meio no comportamento polarográfico do sistema $\mathrm{Cu}(\mathrm{II}) / \mathrm{Cu}(\mathrm{I})$. A determinação das constantes de velocidade da reacção de redução do $\mathrm{Cu}$ (II) pelo sulfito, passando a sulfato em várias condições experimentais, é de grande importância para a compreensão da química do $\mathrm{SO}_{2}$ nas águas das chuvas, nevoeiros, etc. Para se saber até que ponto a reacção de redução do $\mathrm{Cu}$ (II) se pode dar no meio ambiente, tem-se vindo a estudar complexos de cobre(I) produzidos electroquimicamente na interface, com ligandos que estabilizem preferencialmente o cobre(I) como amónia, cloreto e certas aminas.

\section{b) Estudos de processos de interface nas águas naturais}

No âmbito deste tema analisaram-se por polarografia de corrente alterna as propriedades de adsorção de ligandos orgânicos, que simulam algumas propriedades quelantes dos ácidos fúlvicos e por polarografia normal com impulsos algumas características dos seus complexos de cádmio e chumbo, tendo-se determinado nomeadamente a constante de adsorção, a área ocupada por uma molécula de ligando adsorvido e a concentração de complexo na interface em condições de não equilíbrio.

Determinaram-se também as constantes médias e diferenciais do cobre(II), chumbo(II) e zinco(II) com os ligandos de superfície da bactéria Klebsiella Pneumoniae e da alga Selenastrum Capricornutum Printz, para se analisarem os grupo quelantes envolvidos e a percentagem de cada um deles. Estas determinações são importantes porque se trata do primeiro passo na captação dos iões metálicos pelos organismos vivos.

Estudou-se também a adsorção de aminoácidos e a cinética de dissociação dos seus complexos de cobre(II), chumbo(II) e zinco(II) nas condições da água do mar, tendo-se visto a influência dos macroconstituintes cálcio, magnésio e cloreto.

\section{c) Determinaçōes «in situ»}

Dentro deste contexto fizemos estudos sobre o efeito das diferentes espécies químicas na toxicidade do cádmio para camarões Crangon-Crangon, tendo-se procurado relacionar os vários grupos de espécies em solução, em termos de labilidade determinada por voltametria de redissolução anódica e cromatografia de permuta iónica, com o teor de cádmio acumulado nos diferentes tipos de órgãos.

Estudou-se também o efeito de nutrientes, temperatura e luz na assimilação do cádmio pela alga Selenastrum Capricornutrum Printz, tendo-se concluído que as algas vivendo em melhores condições de nutrientes, luz e temperatura segregam mais compostos orgânicos para a solução, formam complexos mais difíceis de se dissociar, protegendo-se assim da sua captação.

Tem-se também vindo a fazer cálculos computacionais para simular resultados experimentais obtidos em certos sistemas ecológicos.

\section{d) Desenvolvimento de métodos electroanalíticos}

Num tema de investigação como este é fundamental compreender-se as possibilidades e limitações dos métodos usados nas condições ambientais.

Assim analisaram-se as possibilidades da voltametria de redissolução anódica para a determinação de iões metálicos em solução e das suas constantes de equilíbrio nas condições das águas naturais, o que tem grande importância visto que se trata da técnica electroanalítica com menores limites de detecção.

Estudaram-se também as possibilidades dos métodos voltamétricos para determinar diferentes tipos de espécies químicas em solução na presença de partículas, tendo-se verificado que os iões metálicos adsorvidos não são detectados, porque são inertes em termos físicos e químicos para a técnica em questão. Podem assim determinar-se os teores de complexos lábeis em solução, alguns complexos inertes com ligandos orgânicos que podem ser reduzidos a potenciais mais negativos e o teor de metais adsorvidos nas partículas por diferença para a concentração total.

Também se estudaram as possibilidades dos métodos voltamétricos para estudos de adsorção nas águas naturais, desde a polarografia com corrente alterna, voltametria cíclica e polarografia normal com impulsos.

Finalmente tem-se vindo a desenvolver as técnicas de injecção em fluxo (flow injection) à análise de águas naturais, em particular na determinação de constantes de estabilidade. 


\section{Referências}

- M.L.S. Simões Gonçalves, L. Sigg e W. Stumm - Voltametric methods for distinguishing between dissolved and particulate metal ion concentrations in the presence of hydrous oxides - A case study on lead(II).

Env. Sci. Technology 19, 141 (1985).

- A.M. Almeida Mota, J. Buffle, J.P. Kounaves e M.L. Simões Gonçalves The importance of concentration effects at the electrode surface in anodic stripping voltammetric measurements of complexation of metal ions at natural water concentrations.

Anal. Chim, Acta, 172, 13 (1985).

- M.M. Correia dos Santos e M.L.S. Simões Gonçalves - Electroanalytical chemistry of copper, lead and zinc complexes of aminoacids at the ionic strenght of seawater.

J. Electroanal. Chem. 208, 137 (1986).

- J. Buffle, A.M. Almeida Mota e M.L.S. Simões Gonçalves - Adsorption of fulvic like organic ligands and their $\mathrm{Cd}$ and $\mathrm{Pb}$ complexes at the mercury electrod.

J. Electroanal. Chem. 223, 235 (1987).

- M.L.S. Simões Gonçalves, M.F. Vilhena e M.A. Sampayo - Effect of nutrients, temperature and light as uptake of cadmium by Selenastrum Capricornutum Printz. Water Research 22, 1429 (1988)

- M.L.S. Simões Gonçalves e A. Lopes da Conceição - Metal ion binding of copper(II), zinc(II) and lead(II) by algae Selenastrum Capricornutum Printz. Sci of Total Env. 78, 155 (1988).

\section{Agradecimento}

Um trabalho deste tipo só se pode fazer com uma equipa de investigação e com projectos conjuntos com entidades nacionais e estrangeiras. A todos se agradece e em especial aos co-autores da bibliografia seleccionada.
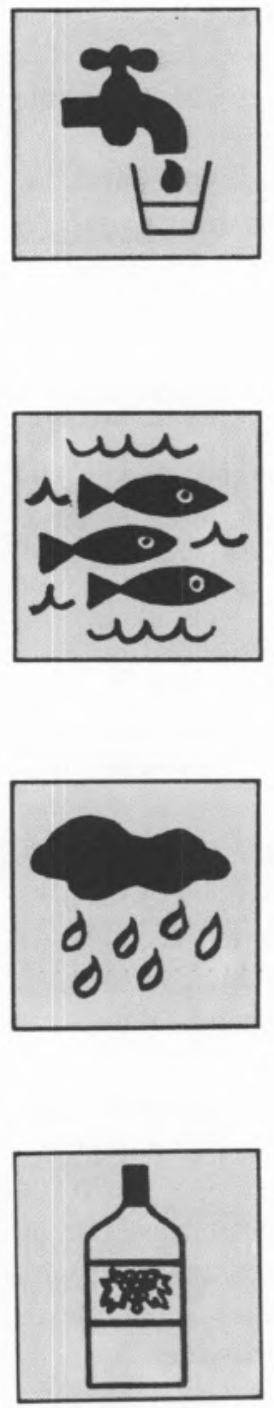

Durante mais de cinco anos, vinhos austríacos adulterados com dietilenoglicol, um composto potencialmente letal, entraram no mercado internacional. Foi em Julho de 1985 que Bruxelas emitiu este alerta. Selecções do Reader's Digest, Fevereiro 1987

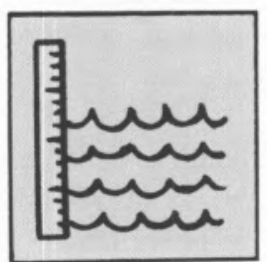

A actividade dos pescadores do estuário do Tejo está ameaçada devido ao alto índice de poluição do rio (principalmente resíduos industriais). Os cardumes de enguias, robalos e linguados começam a rarear em consequência das descargas de produtos tóxicos.

J. Amaro, Semanário, 25 Novembro 1989

O Japão recebe chuva ácida $(\mathrm{pH}=4,4-5,5)$ de provável origem chinesa, apesar de obedecer a medidas altamente restritivas no que respeita à poluição do ar. Este índice, porém, é melhor do que a média da Europa e América do Norte: $\mathrm{pH}=4,0$.

D. Swinbanks, Nature, 340, 671 (1989)

O nível da água do mar está a elevar-se. É possível que o responsável por este fenómeno seja o aumento do "efeito de estufa" dos gases na atmosfera associado a um aquecimento global da Terra. 


\section{Da Química para o Homem Século XX}

1902 - pedras preciosas sintéticas
1903 - soldagem por oxiacetileno

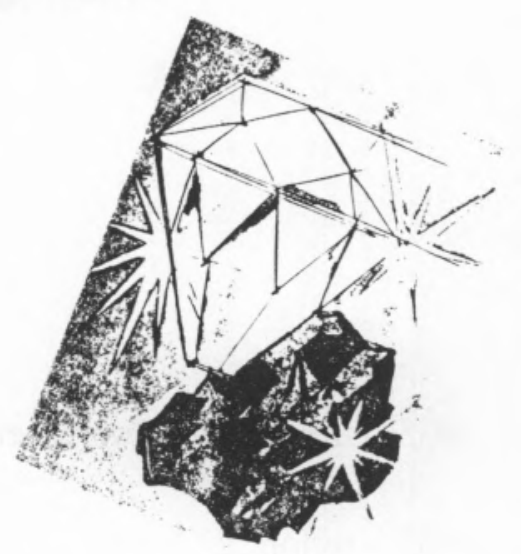

1908 - adubo sintético

1908 - filamento de tungsténio para lâmpadas eléctricas

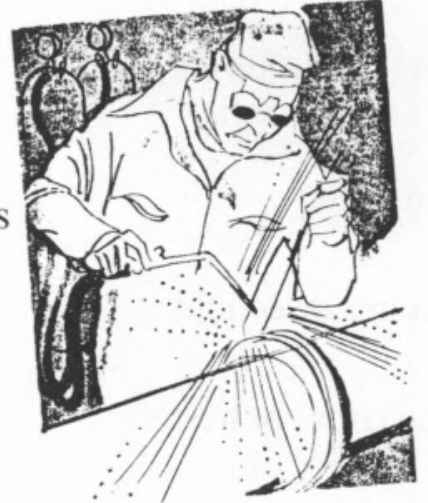

1910 - lâmpada de neon

1929 - espuma de borracha

1929 - tecidos anti-ruga

1930 - lâmpada de flash

1930 - neopreno (borracha sintética)
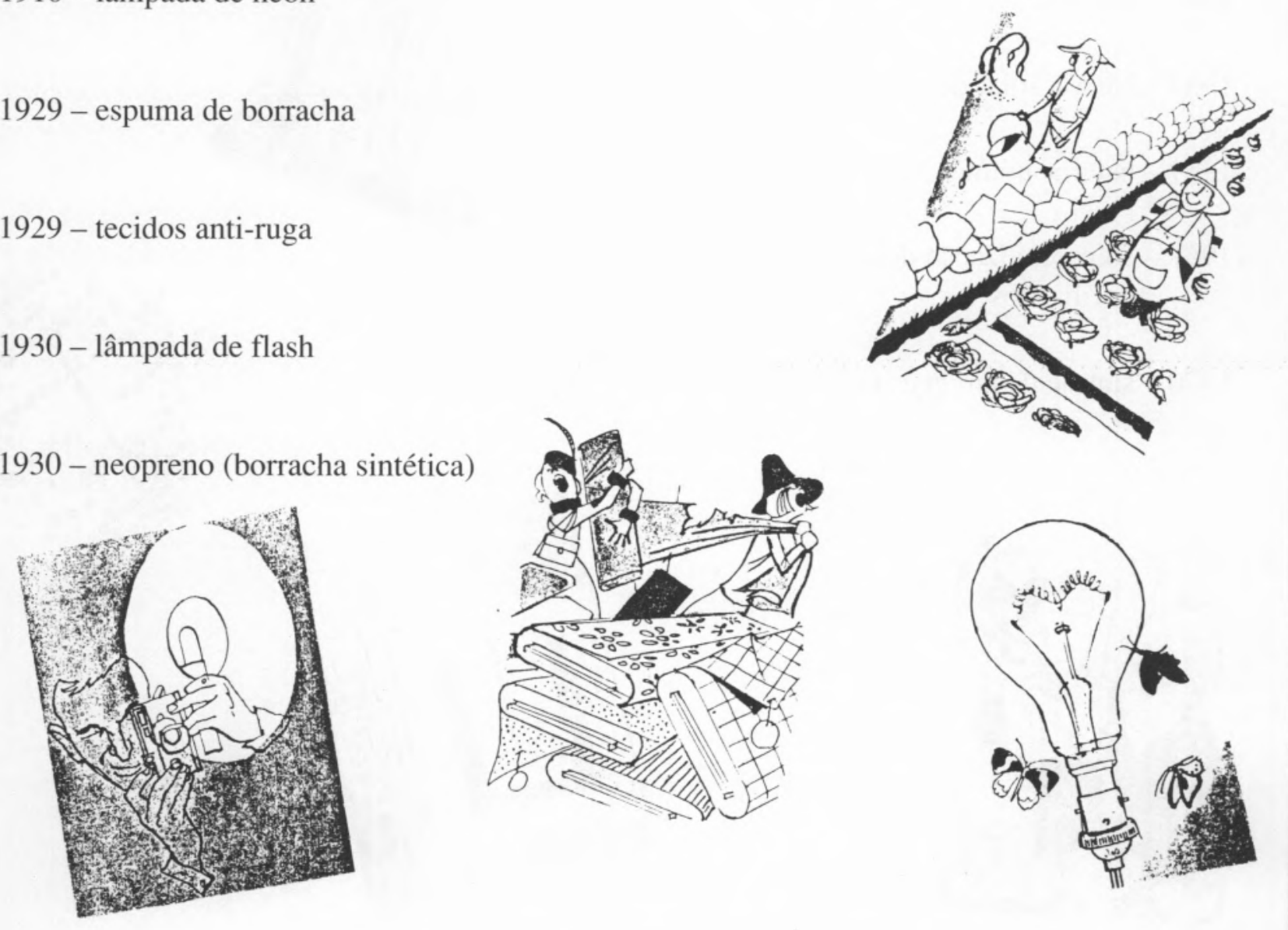


\section{Da Química para o Homem Século XX}

1935 - iluminação fluorescente

1937 - nylon

1937 - cracking catalítico do petróleo

1938 - plástico teflon

1939 - DDT como insecticida

1941 - terylene (fibra poliester)

1946 - silicone

1954 - bateria solar de silício

1959 - bateria atómica

1968 - comercialização dos alimentos liofilizados

1970 - síntese de um gene completo
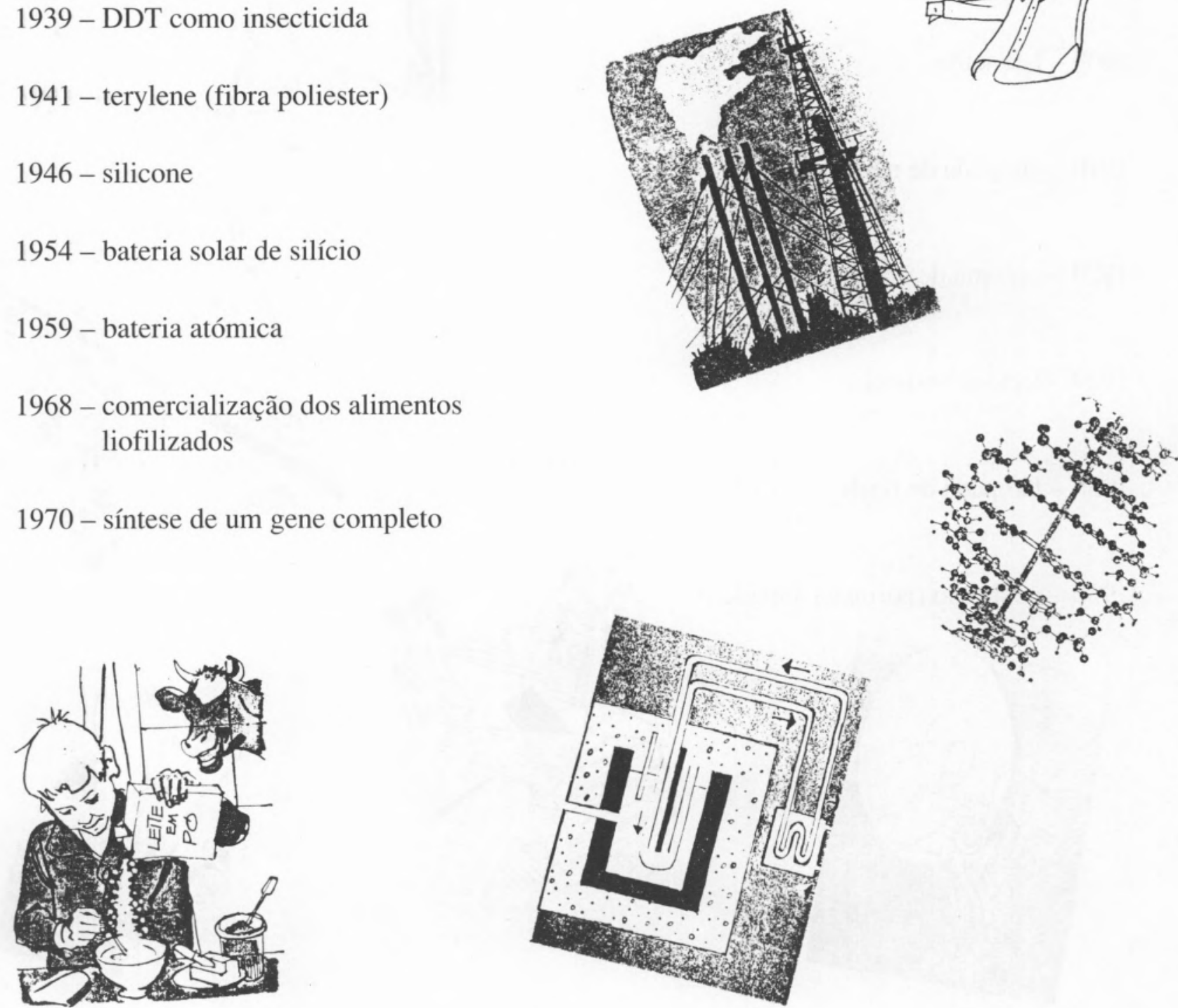